\title{
Gonadotropin-releasing hormone receptor activates GTPase RhoA and inhibits cell invasion in the breast cancer cell line MDA-MB-231
}

Arturo Aguilar-Rojas ${ }^{1,2^{*}}$, Maira Huerta-Reyes ${ }^{1}$, Guadalupe Maya-Núñez ${ }^{2}$, Fabián Arechavaleta-Velásco², P. Michael Conn ${ }^{3}$, Alfredo Ulloa-Aguirre ${ }^{4}$ and Jesús Valdés ${ }^{5}$

\begin{abstract}
Background: Gonadotropin-releasing hormone $(G n R H)$ and its receptor (GnRHR) are both expressed by a number of malignant tumors, including those of the breast. In the latter, both behave as potent inhibitors of invasion. Nevertheless, the signaling pathways whereby the activated $\mathrm{GnRH} / \mathrm{GnRHR}$ system exerts this effect have not been clearly established. In this study, we provide experimental evidence that describes components of the mechanism(s) whereby GnRH inhibits breast cancer cell invasion.

Methods: Actin polymerization and substrate adhesion was measured in the highly invasive cell line, MDA-MB-231 transiently expressing the wild-type or mutant DesK191 GnRHR by fluorometry, flow cytometric analysis, and confocal microscopy, in the absence or presence of GnRH agonist. The effect of RhoA-GTP on stress fiber formation and focal adhesion assembly was measured in MDA-MB-231 cells co-expressing the GnRHRs and the GAP domain of human p190Rho GAP-A or the dominant negative mutant GAP-Y1284D. Cell invasion was determined by the transwell migration assay.

Results: Agonist-stimulated activation of the wild-type GnRHR and the highly plasma membrane expressed mutant GnRHR-DesK191 transiently transfected to MDA-MB-231 cells, favored F-actin polymerization and substrate adhesion. Confocal imaging allowed detection of an association between F-actin levels and the increase in stress fibers promoted by exposure to GnRH. Pull-down assays showed that the effects observed on actin cytoskeleton resulted from GnRH-stimulated activation of RhoA GTPase. Activation of this small G protein favored the marked increase in both cell adhesion to Collagen-I and number of focal adhesion complexes leading to inhibition of the invasion capacity of MDA-MB-231 cells as disclosed by assays in Transwell Chambers.
\end{abstract}

Conclusions: We here show that GnRH inhibits invasion of highly invasive breast cancer-derived MDA-MB-231 cells. This effect is mediated through an increase in substrate adhesion promoted by activation of RhoA GTPase and formation of stress fibers and focal adhesions. These observations offer new insights into the molecular mechanisms whereby activation of overexpressed GnRHRs affects cell invasion potential of this malignant cell line, and provide opportunities for designing mechanism-based adjuvant therapies for breast cancer.

Keywords: Gonadotropin-releasing hormone receptor (GnRHR), Gonadotropin-releasing hormone (GnRH), RhoA GTPase, Cell migration, Cell adhesion, Buserelin

\footnotetext{
*Correspondence: a_aguilar@unam.mx

${ }^{1}$ Centro de Investigación Biomédica del Sur (CIBIS), Instituto Mexicano del

Seguro Social (IMSS), Argentina No. 1, Col. Centro, 62790, Xochitepec,

Morelos, Mexico

${ }^{2}$ Research Unit in Reproductive Medicine, Unidad Médica de Alta

Especialidad-Hospital de Ginecobstetricia No. 4 "Luis Castelazo Ayala" IMSS,

Mexico, DF, Mexico

Full list of author information is available at the end of the article
}

\section{Biomed Central}

(c) 2012 Aguilar-Rojas et al.; licensee BioMed Central Ltd. This is an Open Access article distributed under the terms of the Creative Commons Attribution License (http://creativecommons.org/licenses/by/2.0), which permits unrestricted use, distribution, and reproduction in any medium, provided the original work is properly cited. 


\section{Background}

Breast cancer is the main cause of death from cancer in women. In terms of number of new cases, this malignancy represents the third most frequent cancer and the ratio of mortality to incidence is about 61\% [1]. Chemotherapy is central in the treatment of breast cancer, however it is well known that antineoplastic agents may cause serious adverse and toxic effects [2]. Although malignant breast tumors can be responsive to initial chemotherapy, the development of intrinsic or acquired multidrug resistance limits malignant tumor cells treatments and restricts subsequent responses to therapy $[2,3]$. Development and growth of metastases at distant sites are the principal cause of death among breast cancer patients, being responsible for approximately $90 \%$ of deaths from this malignant disease [4,5]; further, in metastatic tumors, the response rates to first line chemotherapies, either by single or combined drugs, range from $30-70 \%$ with remission periods following treatment of only 7-10 months [3]. Therefore, the development of alternative therapies to prevent or ameliorate the fatal course of this disease is essential.

The metastatic process comprises an ordered series of events in which the acquisition of a motile and invasive phenotype to penetrate the extracellular matrix (ECM) is one of the earliest steps and a key determinant of the invasive potential of tumor cells [6]. During cell migration, the so-called focal adhesion complex (FA) serves as a point of control for cell migratory potential by regulating the continuous formation and turnover of cell substratum contacts as well as actin polymerization. The regulation of actin cytoskeleton during cell locomotion and adhesion is performed by small $G$ proteins from the Rho family, which comprises several members, including RhoA, Rac1, and Cdc42 [7]. RhoA is responsible for the development of stress fibers and focal adhesion assembly [8]. Although the specific mechanisms that control the assembly of the FA and cell substrate-adhesion factors are not well understood, the importance of RhoA in this process has been demonstrated by in vitro studies. For example, in cultured cells low levels of activated-RhoA have been found to be associated with a high migration phenotype $[9,10]$ whereas, in contrast, high RhoA activity has been linked to poor migration ability by high substrate adhesion [11-13]. Thus, it appears that RhoA is a key regulator of cell adhesion and motility in cancer cells.

Gonadotropin-releasing hormone (GnRH), a decapeptide synthesized in the hypothalamus, and its receptor, the gonadotropin-releasing hormone receptor (GnRHR), a $G$ protein-coupled receptor located in the membrane of the gonadotrophs of the anterior pituitary [14], are key regulators of reproductive function. However, it has been found that the GnRHR is not exclusively expressed in the anterior pituitary gland but also in other reproductive tissues such as the breast, endometrium, ovary, and prostate as well as in tumors derived from these tissues, where it probably regulates cell proliferation and tumor invasiveness [15-18]. In fact, GnRH and some of its agonists have shown to be effective in controlling tumor growth and invasiveness in in vitro and in vivo systems [19-21]. Further, several studies have shown that the ability of the GnRH/GnRHR system to reduce cell tumor invasion and metastatic potential are associated with up regulation of actin cytoskeleton remodeling, mainly through the activation of Rac1 [22,23] as well as by influencing the activity of cell-cell adhesion molecules and/or the regulation of cell substrate attachmentassociated proteins [24,25]. These observations have provided new insights into opportunities for adjuvant therapies based on disruption of these processes.

Approximately 50-60\% of breast cancer tumors as well as several breast cancer-derived cell lines express specific binding sites for GnRH [26,27]. The role of GnRH and $\mathrm{GnRH}$ agonists (GnRHa) to inhibit growth of breast cancer cells has been demonstrated in both in vitro [18] and in vivo models $[15,16,19]$. Likewise, the ability of GnRH and $\mathrm{GnRHa}$ to reduce the migratory potential of these cells has also been established [20,21]. Nevertheless, at this point much less is known about the molecular mechanisms subserving the effects of the GnRH/GnRHR system to inhibit breast cancer cells migration. A key point in this process might be the regulation of the cytoskeleton and extracellular matrix (ECM)-adhesion.

In the present study, we analyzed the molecular mechanisms employed by the human GnRHR to regulate cell motility in the highly invasive breast cancer cell line MDA-MB-231. We found that GnRHR activation by the GnRHa, Buserelin, affected several cellular markers of locomotion, including actin organization and polymerization as well as active RhoA-GTP levels. The cellular modifications observed correlated with high levels of cell adhesion and FA assembly, and inhibition of trans-well invasion.

\section{Methods}

\section{Cell culture}

The highly invasive breast cancer cell line, MDA-MB231 (MDA) [28] was obtained from the American Type Culture Collection (ATCC, Manassas, VA, USA). The MDA cells were cultured in Leibovitz's medium supplemented with antibiotics and 10\% fetal calf serum (FCS) (Invitrogen, Carlsbad CA, USA) in a humidified chamber at $37^{\circ} \mathrm{C}$ and $5 \% \mathrm{CO}_{2}$. The breast cancer line MCF-7 (ATCC), was cultured in Dulbecco's modified Eagle's medium (DMEM) (Invitrogen) supplemented with 10\% FCS and antibiotics at $37^{\circ} \mathrm{C}$ and $5 \% \mathrm{CO}_{2}$ in a humidified atmosphere. 


\section{Constructions}

Wild-type (WT) GnRHR (GeneBank access number L07949; [29]) and mutant GnRHR lacking lysine at position 191 (at the extracellular loop 2) (GnRHR-DesK191) cDNAs, cloned in the expression vector pcDNA3.1 (Invitrogen) at Kpn1 and Xba1 sites (New England BioLabs, Ipswich MA, USA) were synthesized as described previously [30]. As previously shown [31], the GnRHRDesK191 is expressed at higher levels compared to the WT receptor. The coding cDNA region of the human guanine activating protein domain (GAP; amino acid residues 1248 to 1431) of the Rho-activating protein, p190Rho GAP-A (GeneBank access number AF159851; [32]) was isolated from total MCF-7 cells RNA by RT-PCR, and cloned into the pcDNA3.1 vector at the restriction site Xho1 (New England BioLabs). The dominant negative mutant of the GAP domain (GAP-Y1284D) [33], was constructed employing the QuickChange site-directed mutagenesis kit (Stratagene, La Jolla, CA, USA); the mutagenic oligonucleotide primers (Invitrogen) were designed according to the sequence of the GAP domain mentioned above. The fidelity of all constructions was verified by dye terminator cycle sequencing (Perkin Elmer, Foster City CA, USA).

\section{Transient transfection of MDA-MB231 cells}

Wild-type and modified cDNA constructions were transiently expressed in MDA cells. Transfections (800 ng DNA/ well) were performed employing the FuGENE HD transfection reagent (Roche Applied Science, Sandhofer, Mannheim, Germany) following the manufacturer's protocol. Briefly, MDA cells were trypsinized and $\sim 250,000$ cells/well were plated in 12-well culture plates (Costar, Cambridge, MA, USA). For co-transfections, cells were transfected with WT GnRHR and GAP domain cDNAs (GAP cells) or WT GnRHR and GAP-Y1284D domain (GAP-Y1284D cells) cDNAs at a 1:1 ratio. Experiments were performed 24 hours after transfection. Cells transfected with empty pcDNA3.1 vector were employed as negative controls.

\section{Radioligand binding assays}

Radioligand binding assays were performed as previously described [34]. Briefly, 100,000 cells per well were plated in 24-well plates (Costar) and transfected as described above. Twenty-four hours after start the transfection, cells were washed twice with Lebovitz medium and $0.1 \%$ BSA (Sigma, St. Louis MO, USA), and kept in FCS-free growth media for 18 hours. Thereafter, cells were washed twice and incubated at room temperature for 90 minutes in the presence or absence of excess $(10 \mu \mathrm{M})$ unlabeled Buserelin (Sigma) plus $\left[{ }^{125} \mathrm{I}\right]$-Buserelin (specific activity, $700 \mathrm{mCi} / \mathrm{mg}$ ). After the incubation, the medium was removed and the cells were washed twice with ice-cold PBS. Cells were then solubilized in $0.2 \mathrm{M}$ $\mathrm{NaOH} / 0.1 \%$ SDS and counted.

\section{Measurement of inositol phosphate (IP) production}

Inositol phosphates (IP) production was measured in cells cultured in inositol phosphate-free medium and preloaded with $4 \mu \mathrm{Ci} / \mathrm{ml}\left[{ }^{3} \mathrm{H}\right]$-myo-inositol (New England Nuclear, Boston MA, USA) for 18 hours at $37^{\circ} \mathrm{C}$, as previously described $[31,35]$. Transfected cells $(50,000$ cells/well) were exposed to Buserelin $\left(10^{-11}\right.$ to $\left.10^{-7} \mathrm{M}\right)$ for 2 hours and then washed twice with inositol-free medium supplemented with $5 \mathrm{mM} \mathrm{LiCl}$. Quantification of IP was determined by Dowex anion exchange chromatography and liquid scintillation spectroscopy.

\section{Measurement of F-actin}

The amount of actin polymerized (F-actin) in adherent cells stimulated with Buserelin was determined by fluorometry [36] in transfected cells (250,000 cells/well) stimulated with $10^{-7} \mathrm{M}$ Buserelin for 24 hours. Cells were then fixed with 3.7\% formaldehyde (Sigma) in PBS for 10 minutes, and permeabilized with $0.1 \%$ Triton X-100 (Sigma) in PBS for 1 minute. F-actin was stained by incubating with $0.165 \mathrm{mM}$ rhodamine-conjugated phalloidin (Molecular Probes, Eugene OR, USA) during 20 minutes in the dark at room temperature. Rhodamine bound to F-actin was removed with methanol and read in a Fluroskan Ascent Microplate Fluorometer (Thermo Scientific, USA) at 554 $\mathrm{nm}$ for excitation and $573 \mathrm{~nm}$ for emission. To determine the relative amount of rhodamine bound to F-actin per cell, five randomized fields per well were counted after methanol extraction [37]. The relative F-actin content was expressed as the amount of rhodamine-phalloidin per cell in Buserelin-stimulated samples divided by the amount of rhodamine-phalloidin per cell in control samples [38].

The amount of F-actin in suspended, GnRHa-stimulated cells was determined by flow cytometric analysis [36]. Briefly, transfected cells in suspension (50,000 cells/tube) were incubated in the absence or presence of $10^{-7} \mathrm{M}$ Buserelin for 2 hours at $37^{\circ} \mathrm{C}$. Cell suspensions were then fixed with $3.5 \%$ formaldehyde and quenched in $0.1 \mathrm{M}$ glycine for 30 minutes. After permeabilizing with $0.2 \%$ Triton X-100-1\% BSA, cells were stained with 0.165 $\mathrm{mM}$ rhodamine-phalloidin for 30 minutes. The amount of F-actin was measured in a FACSAria flow cytometer (Becton Dickinson, Franklin Lakes, NJ, USA) at $554 \mathrm{~nm}$ excitation and $573 \mathrm{~nm}$ emission. At least 1000 events per sample were analyzed. Data analysis was performed using the Summit software version 4.3 (Dako Colorado Inc, USA); the results expressed as the mean of fluorescence intensity (rhodamine-phalloidin in Buserelin-stimulated samples/rhodamine-phalloidin in control samples).

\section{Confocal microscopy of F-actin}

Arrangement of F-actin in transfected cells was visualized by confocal microscopy as described elsewhere [36]. Cells cultured on Histogrip (Invitrogen)-coated 
coverslips were incubated in serum-free medium with Buserelin $\left(10^{-7} \mathrm{M}\right)$ during 24 hours. F-actin was stained as described above and mounted on slides cover with ProLong solution (Invitrogen). Samples were then visualized in a Leica TCS SP5 MP multiphoton microscope (Leica Microsystems, Wetzlar, Germany).

Focal adhesion (FA) and F-actin arrangement in adherent cells to Collagen I were also evaluated by confocal microscopy. Collagen I (Sigma)-coated coverslips were placed in 24-well plates and transfected. Twenty-four hours after transfection, cells $(80,000 /$ well) were stimulated with Buserelin and stained with rhodaminephalloidin as described above. Mouse anti-vinculin IgG monoclonal antibody (at a 1:200 dilution in PBS) and FITC-conjugated anti-mouse IgG antibody (Millipore, Temecula CA, USA) were added in tandem to visualize focal adhesion [39]. Samples were mounted and visualized as described above.

\section{Measurement of Rho activity}

Cells were plated in Collagen I-precoated, $10 \mathrm{~mm}$ culture dishes (at a density of $2.125 \times 10^{6}$ cells/dish), transfected and exposed to $10^{-7} \mathrm{M}$ of Buserelin in Lebovitz's medium for 24 hours. Measurement of GnRHa-stimulated active RhoA-GTP was performed by a pull-down assay employing the Rho-binding domain (RBD) of Rhotekin coupled to glutathione-S-transferase-sepharose (GST) (GE Healthcare Bio-Science, Uppsala, Sweden) and subsequent immunoblotting. RhoA-GTP was eluted with Laemmli buffer following the protocol described previously with minor modifications [40]. Eluates were electrophoresed in 7.5\% SDS-PAGE and transferred to polyvinylidene fluoride membranes (Millipore), and blots were probed with mouse anti-Rho monoclonal antibody (Millipore) at a 1:1000 dilution. RhoA-GTP and total RhoA (from no pulldown control extracts) levels were measured by densitometry. Results are expressed as the ratio of RBD/GST-bound Rho (RhoA-GTP)/total RhoA levels.

\section{Adhesion assays to Collagen I}

Cell adhesion to Collagen I was determined by a colorimetric assay [41]. Transfected cells (20,000/well) cultured in Collagen I-coated 96-well plates were incubated for 24 hours at $37^{\circ} \mathrm{C}$ in FCS-free medium in presence or absence of Buserelin $\left(10^{-7} \mathrm{M}\right)$. Adherent cells were fixed and stained with $0.1 \%$ crystal violet (Sigma) in methanol. The absorbance of sodium citrate $(0.1 \mathrm{M})$-extracted dye was then measured at $595 \mathrm{~nm}$.

\section{Quantification of F-actin during cell adhesion and cell invasion}

The amount of F-actin present in transfected, Collagen I-adherent cells incubated in the presence or absence of Buserelin $\left(10^{-7} \mathrm{M}\right)$ as well as that present during of invasiveness conditions (i.e. cells cultured in the presence of FCS (10\%)) were measured by fluorometry following the protocol described above [42].

\section{Invasion assays}

Invasion assays were carried out in $6.5 \mathrm{~mm}$, Collagen I (10 mg/ml)-coated Transwell Chambers separated by a semipermeable membrane with a $8-\mu \mathrm{m}$ pore size (Costar) [43]. Cells were transfected as described above, detached from culture plates and resuspended in serumfree Leibovitz's medium containing 0.1\% BSA. One hundred thousand cells were added to the upper chamber and then incubated in the presence or absence of $10^{-7} \mathrm{M}$ of Buserelin. Cells were allowed to migrate to the lower chamber (containing Leibovitz's medium/10\% FCS, with or without $\mathrm{GnRHa}$ ) during $24 \mathrm{~h}$ at $37^{\circ} \mathrm{C}$ in $5 \% \mathrm{CO}_{2}$, and migrated cells were collected, pelleted, resuspended in PBS, and counted [44].

\section{Statistical analysis}

All experiments were performed in triplicate incubations. Data were analyzed by one-way analysis of variance (ANOVA) followed by the Tukey's multiple comparison test. A value of $P<0.05$ was considered statistically significant. Statistical tests were performed using the GraphPad software (GraphPad Software Inc., v. 4.1, La Jolla, CA, USA).

\section{Results}

Expression and functionality of transfected GnRHRs in MDA-MB-231 breast cancer cells

Specific binding sites for $\left[{ }^{125} \mathrm{I}\right]$-Buserelin and IP production in response to agonist exposure were detected in WT GnRHR-transfected cells. Since plasma cell surface expression of the transfected WT GnRHR was relatively low in this tumor cell line, the over-expressed mutant form, GnRHR-DesK191 was also employed to explore the effect of increased cell surface membraneexpressed receptor levels on several cell markers associated with locomotion dynamics. Compared to the WT GnRHR, specific $\left[{ }^{125} \mathrm{I}\right]$-Buserelin binding and Buserelinstimulated IP production of cells transfected with the GnRHR-DesK191 were considerably increased (to $139 \pm$ $19 \%$ and $590 \pm 134 \%$ of WT levels, for total binding and IP production, respectively) (Figures $1 \mathrm{~A}$ and $\mathrm{B}$ ). Relative $\left[{ }^{125} \mathrm{I}\right]$-Buserelin binding affinities were similar for the endogenous receptor (empty vector-transfected) $\left(K_{i}, 1.03 \pm\right.$ $0.20 \mu \mathrm{M})$, and the WT $\left(K_{i}, 0.50 \pm 0.15 \mu \mathrm{M}\right)$ and DesK191 $\left(K_{i}, 0.70 \pm 0.20 \mu \mathrm{M}\right)$ transfected GnRHRs, as disclosed by radioligand-binding assays. Nevertheless, the IP response was considerably reduced (by $\sim 80 \%$ ) in cells transfected with the empty vector, thus reflecting the low levels of endogenously expressed GnRHR in MDA-MB-231 breast cancer cells (Figures 1A and B). 


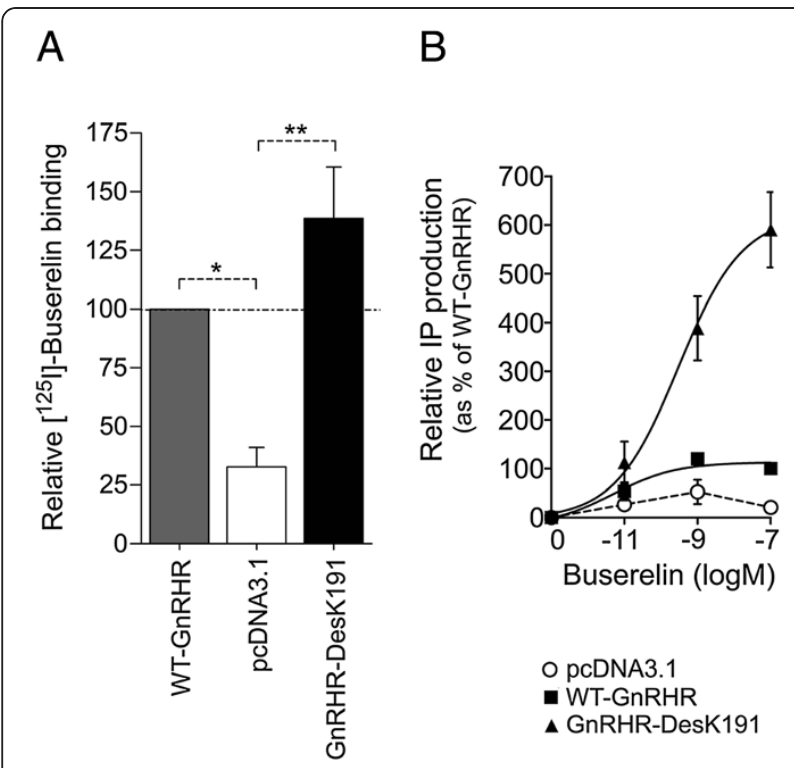

Figure $1\left[{ }^{125} \mathrm{I}\right]-$-Buserelin binding and IP production in MDA cells expressing the WT GnRHR and GnRHR-DesK191 mutant. A. Specific [ $\left.{ }^{125} \mathrm{I}\right]$-Buserelin binding to MDA cells transfected with the empty vector (pcDNA3.1), the WT GnRHR and the GnRHR-DesK191 cDNA constructs. B. Inositol phosphate dose-response curves for Buserelin in MDA cells transiently expressing the WT GnRHR and GnRHR-DesK191 mutant. Maximal IP production in cells transfected with the WT GnRHR CDNA was set as 100\% and all other values are expressed relative to this. Assays were performed in triplicate incubations and the results shown are the means \pm SEM from three independent experiments. ${ }^{*} p<0.001$; ${ }^{* *} p<0.01$ vs $p c D N A 3.1$.

\section{Effect of buserelin-stimulated GnRHR in actin polymerization}

The effect of GnRHR in F-actin cytoskeleton remodeling was assessed in adherent MDA cells exposed to a saturating concentration of Buserelin $\left(10^{-7} \mathrm{M}\right)$. F-actin was stained with rhodamine-phalloidin and quantified for fluorometry. A significant $(\mathrm{p}<0.05)$ increase in the relative amount of F-actin in WT and DesK191 GnRHRsexpressing cells was observed in response to Buserelin (Figure 2A). Although the amount of F-actin was higher in cells transfected with the GnRHR-DesK191 than in those transfected with the WT receptor, the difference did not reach statistical significance. Conversely, actin polymerization promoted by Buserelin-stimulated GnRHR and GnRHR-DesK191 was significantly decreased in nonadherent $(\mathrm{p}<0.05$; Figure $2 \mathrm{~B})$. Thus, GnRH promoted actin polymerization only in adherent cells.

Actin cytoskeleton arrangement after GnRHR activation in MDA cells

Although the images did not show any substantial change in the morphology of cells expressing the WT and DesK191 GnRHRs in response to a saturating concentration of Buserelin (Figures 2C 1 and 4), a remarkable increase in stress fibers crossing the cell body was observed as a result of GnRHa exposure (Figures 2C 2-3 and 5-6).

\section{Rho activity in MDA cell adhered to Collagen I}

The increase of F-actin as stress fibers in cells exposed to Buserelin, strongly suggested that the GnRH/GnRHR system might be linked to activation of RhoA GTPase, which is responsible of stress fiber formation and focal adhesion assembly [8]. To determine the impact GnRHR activation on RhoA response, the levels of GTP-loading RhoA were analyzed in MDA cells adhered to Collagen I and stimulated with Buserelin. Negligible levels of GTPRhoA were observed in cells transfected with the empty pcDNA3.1 vector, even in the presence of saturating concentrations of Buserelin (Figure 3A). In contrast, GTP-RhoA levels were significantly $(p<0.01)$ increased in GnRHa-stimulated WT GnRHR- and GnRHRDesK191-transfected cells, indicating that RhoA was activated by $\mathrm{GnRH}$ in MDA cells. In order to more deeply explore the association between RhoA and GnRHR activation in these cells, the GAP domain of p190RhoGAP as well as the dominant negative form of this domain (GAP-Y1284D) were co-transfected with the GnRHR and the Rho-GTP levels were determined after Buserelin stimulation. Under these conditions, GTP-RhoA protein levels were either suppressed or unaffected in cells transfected with the GAP domain or the GAP-Y1284D, respectively (Figure $3 \mathrm{~A}$ and $\mathrm{B}$ ).

\section{Attachment to Collagen I and quantification of F-actin in MDA cells}

Cell attachment to the ECM is a function linked to RhoA and actin cytoskeleton dynamics [45]. Keeping this in mind, the effects of GnRHR activation on Collagen I adhesion and actin polymerization during this condition were determined. A substantial increase in cell adhesion following GnRHa stimulation was observed in WT GnRHR-, GnRHR-DesK191-transfected, and GAP-Y1284D/ GnRHR-co-transfected cells. By contrast, Buserelinstimulated adhesion was completely abolished in GAP domain/GnRHR-co-transfected cells (Figure 3C). As expected, the amount of F-actin in cell adhesion conditions was increased $(\mathrm{p}<0.01)$ after Buserelin activation in GnRHR-, GnRHR-DesK191- and GAP-Y1284D-transfected cells. Interesting, although in cells transfected with the GAP domain the amount of F-actin was the highest, polymerized actin was observed only in the periphery but not across the cell body (see below).

\section{Arrangement of focal adhesion and F-actin upon GnRHR activation in MDA cells}

Cell attachment takes place through formation of focal adhesion complexes via RhoA activity [46]. These adhesion complexes favor the interactions between ECM- 
A

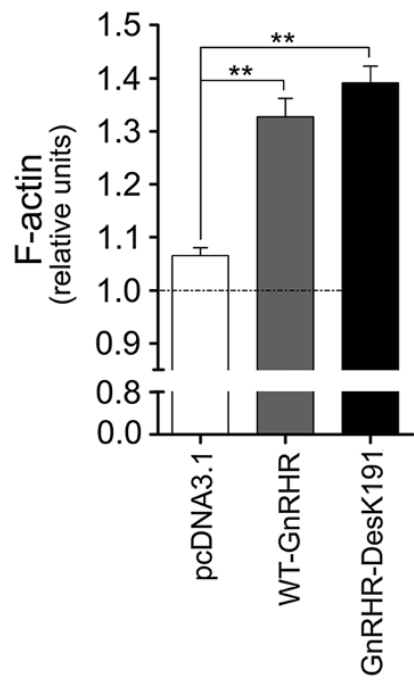

B

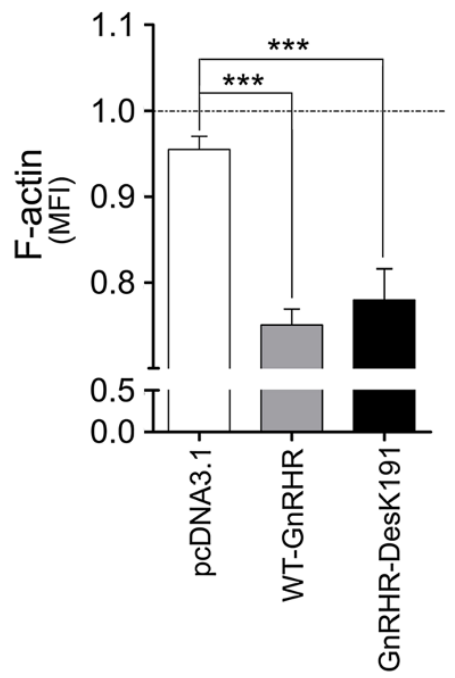

C
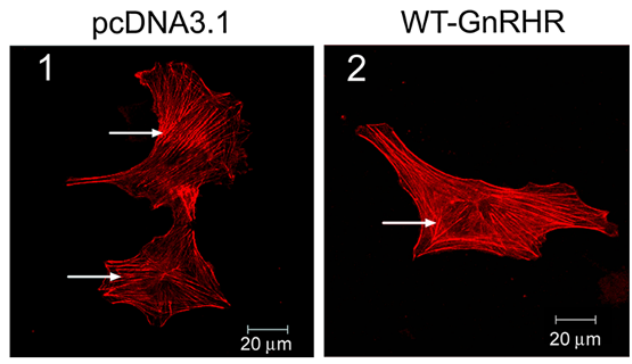

GnRHR-DesK191
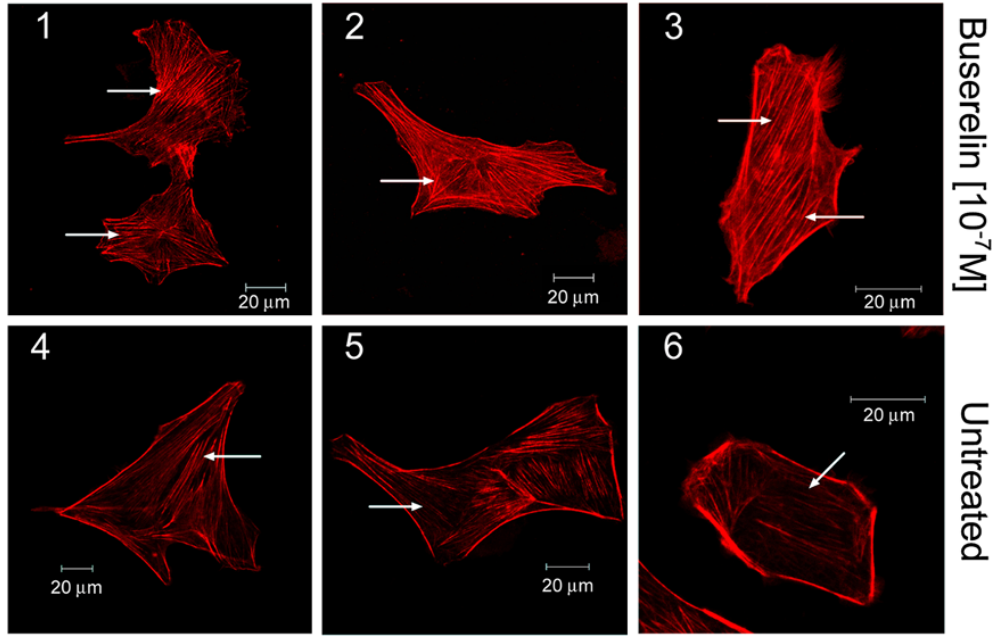

Figure 2 Effects of Buserelin on actin polmerization in MDA cells. A. Buserelin (10 $10^{-7} \mathrm{M}$ )-stimulated relative F-actin levels (in arbitrary units) in adherent MDA cells transfected with the empty vector, the WT GnRHR or the GnRHR-DesK191 CDNAs, as determined by fluorometry. Cells expressing the WT and DesK191 GnRHRs exhibited a significant increase in polymerized actin in response to the GnRHa. In each group (cells transfected with the empty vector, WT GnRHR or GnRHR-DesK191), basal F-actin (i.e. no treatment) was set to 1.0 and Buserelin-stimulated levels were expressed relative to this (horizontal line). B. Relative F-actin levels measured by flow cytometry in suspended MDA cells transfected with the empty vector, the WT GnRHR or the GnRHR-DesK191 cDNA constructs. A significant decrease in polymerized actin was observed in response to the GnRHa. C. Representative images from confocal microscopy of Buserelin $\left(10^{-7} \mathrm{M}\right)$-stimulated MDA cells transfected with the empty vector, the WT GnRHR or the GnRHR-DesK191 cDNAs. Compared with untreated cells (lower panel) an increase in stress fibers (arrows) was apparent in

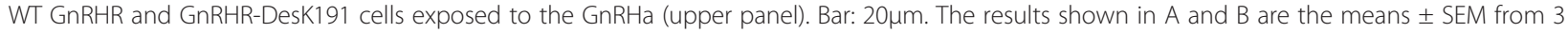
independent experiments. ${ }^{* *} p<0.05 ;{ }^{* * *} p<0.05$.

linked integrins and the actin cytoskeleton, as well as with a number of other cytoplasmic proteins, including talin, vinculin, paxillin, and alpha-actinin [47]. Since formation of focal adhesion reflects cell adhesion to the ECM, identification of these structures by vinculin immunostaining was conducted in transfected MDA cells plated on Collagen I. In agonist-stimulated GnRHR,
GnRHR-DesK191 and GAP-Y1284D-transfected cells, accumulation of intense fluorescent dots revealed the presence of FA as well as high amount of stress fibers across the cell body (Figure 4A, compare arrows in panels 2, 3 and 5 with arrows in panels 7, 8 and 10). On the other hand, treatment of GAP domain-transfected cells led to complete absence of fluorescent vinculin dots 


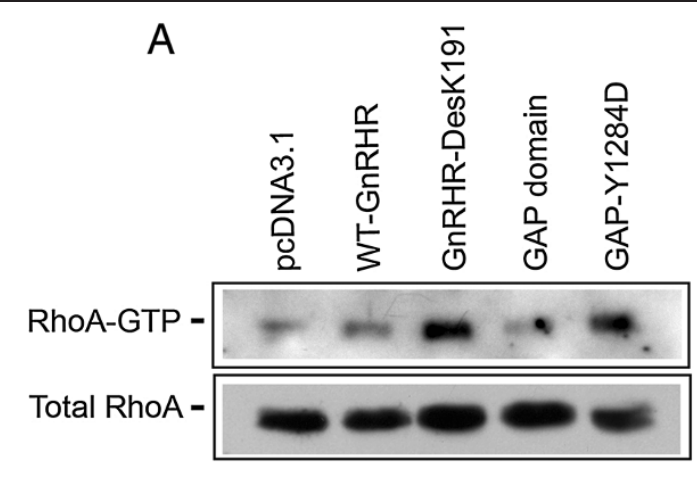

B

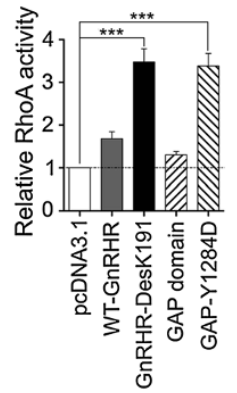

C

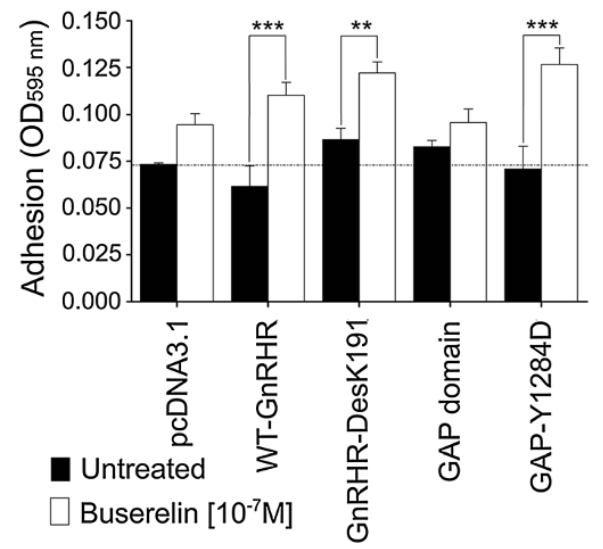

$\mathrm{D}$
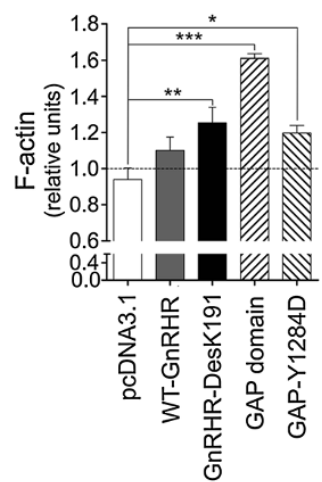

Figure 3 Effects of Buserelin on RhoA GTP expression and cell adhesion to Collagen I in MDA cells. A. Representative autoradiogram from Western blots showing the effects of Buserelin on RhoA expression in MDA cells transfected with the empty vector, the WT GnRHR and the GnRH-DesK191 cDNAs (lanes 1 to 3) or co-transfected with the WT GnRHR and p190RhoGAP or GAP-Y1284D cDNAs (lanes 4 and 5, respectively). B. Densitometric analysis of Rho GTP activity as determined by pull-down assays and Western blotting of extracts from cells transfected or cotransfected with the different expression plasmids and exposed to $10^{-7} \mathrm{M}$ Buserelin or vehicle. C. Assessment of adhesion to Collagen I in cells transfected or co-transfected with the different GnRHRs and GAP expression plasmids described in A and exposed to Buserelin or vehicle. D. Relative F-actin levels in the cell adhesion experiments shown in C, as disclosed by fluorometry. The results shown in $B, C$, and D are the means \pm SEM from 3 independent experiments. ${ }^{*} p<0.05 ;{ }^{* *} P<0.01 ;{ }^{* * *} p<0.001$.

and abolishment of stress fibers formation, indicating absence of FA in these particular cells. As noted above, high amounts of peripheral F-actin were detected in GAP-domain-transfected cells (Figure 4A, compare arrows in panels 4 and 9 with arrows in panels 1 and 6).

\section{Effects of GnRHR activation on invasion to Collagen I and measurement of F-actin in invasion conditions}

Since RhoA plays a pivotal role in cell migration through regulating cytoskeletal changes and matrix adhesion dynamics [46], invasion of MDA cells transfected with the GnRHRs to Collagen I was evaluated. In Transwells Chambers covered with Collagen I and stimulated with Buserelin, GnRHR-, GnRHR-DesK191, and GAP-Y1284Dtransfected cells showed a substantial reduction in invasion ability (Figure 4B). This inhibition was abrogated in the absence of active GTP-RhoA (GAP-domain-transfected cells) (Figure 4B). Measurement of polymerized actin during invasion showed that in contrast to control, empty vector-transfected cells, GnRHR and mainly GnRHR-DesK191 and GAP-Y1284D-transfected cells exhibited a marked increase in the amount of F-actin in the presence of Buserelin (Figure 4C), a finding that correlated with their ability to adhere to Collagen I under similar conditions (Figure 4B). Analogously with the adhesion experiments (see above), the amount of F-actin detected in invasion assays was the highest in GAP domaintransfected cells (Figure 4C).

\section{Discussion}

Metastases at distant sites are the main cause of death in patients with breast cancer [48]. The metastatic process involves a series of events in which changes in cell motility represent the hallmark of invasion and the initial step in metastasis [6]. Over the past years, it has been clearly established that $\mathrm{GnRH}$ and its receptor are 


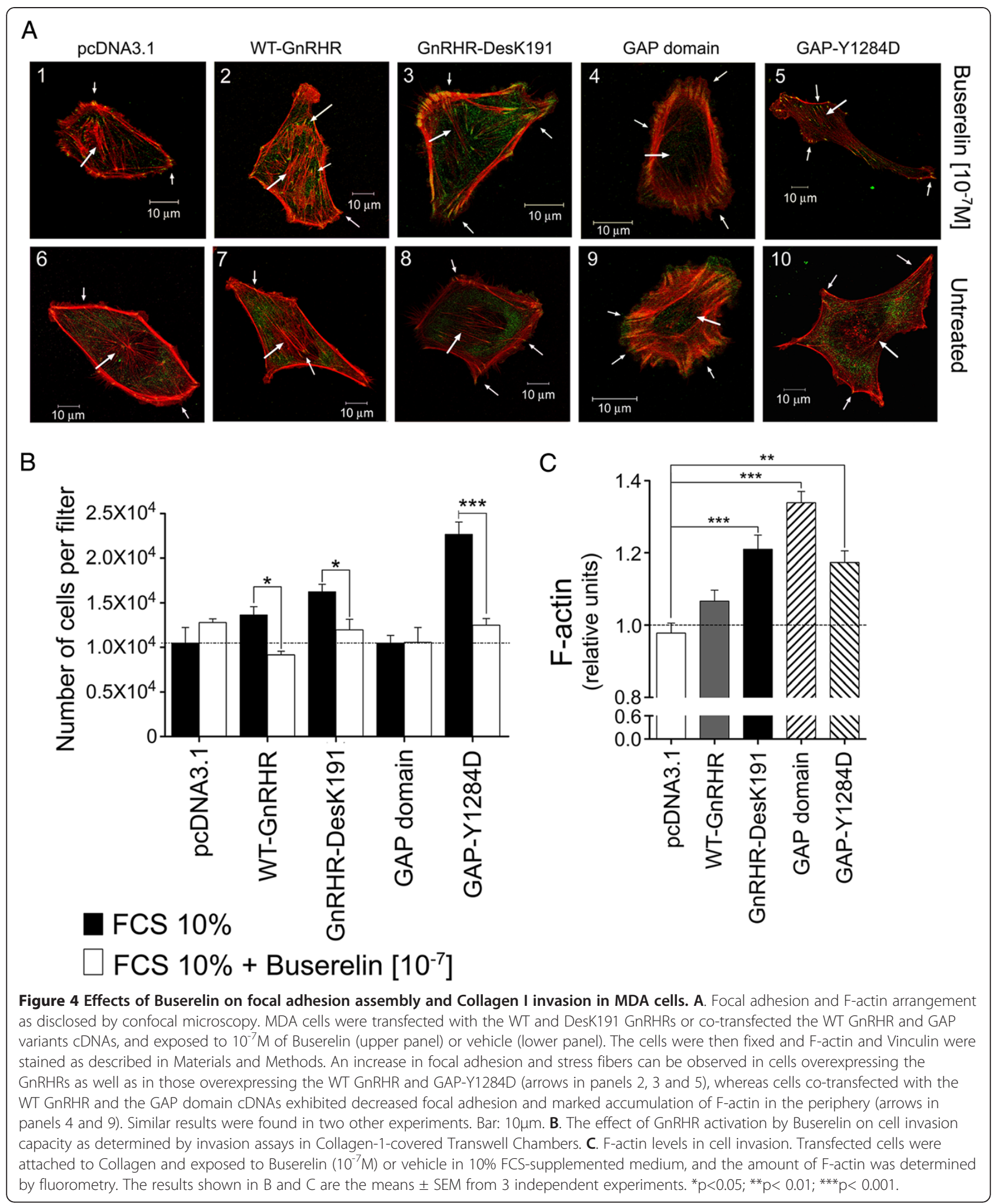

expressed in many extra-pituitary tissues and malignant tumors from the reproductive system, including the breast [26,27]. It has also been shown that binding of $\mathrm{GnRH}$ to breast malignant tumor cells results in growth modulation [18] and inhibition of metastatic capacity [20]. Although activation of some signaling pathways and effectors proteins involved in GnRHR-regulated cell motility have been reported [17,24], the molecular 
mechanism(s) whereby the GnRH/GnRHR system suppresses cell migration is still unclear.

In the present study we assessed the effect of GnRH on the invasiveness capacity of human breast cancer MDA-MB-231 cells, an aggressive, highly invasive, and estrogen unresponsive cell line [49]. To this end, we overexpressed the GnRHR in MDA cells and analyzed the effects of its cognate ligand on the pathways leading to actin cytoskeleton activation and cell adhesion. MDA cells transfected with the GnRHR (WT and DesK191) cDNAs, specifically bound $\left[{ }^{125} \mathrm{I}\right]$-Buserelin and produced higher levels of the second messenger IP in response to the GnRH analog than untransfected cells, overcoming the problem related to the low naturally expressed GnRHR levels in breast cancer cell lines [50,51]. In fact, the increased expression levels and IP response to GnRHa detected in GnRHR-transfected MDA cells, emulated those previously detected in breast cancer cells exhibiting high GnRHR expression levels [52]. Here we confirm that to detect relevant effects of $\mathrm{GnRH}$ on breast cancer cells function, it is necessary to substantially increase cell surface plasma membrane receptor levels, which is an important issue given that the number of GnRHRs is highly variable in malignant breast tumors tissue [51]. In this scenario, measurement of GnRHR density in malignant breast tissue may be useful as a surrogate marker to predict the tumor responsiveness to GnRHa administration.

We have shown that in MDA cells, GnRHRs were able to promote IP production upon activation by agonist. Although we did not detect measurable changes in cAMP levels after exposure to GnRHa in this particular cell line (not shown), previous studies have found that the inhibitory effects of GnRHa on other reproductive cancers (including prostate and endometrial cancer) is mediated by the $G_{\alpha i}$ protein [53-55]. Our data are consistent with previous studies in MCF-7 breast cancer cells, in which the GnRH/GnRHR system was capable to selectively promote IP production [52]. These data support the idea that in extrapituitary tissues, the GnRHR may couple to different $G$ proteins and activate distinct signaling pathways depending on the cell context, the particular GnRH analog employed to activate the receptor, and also probably the receptor density $[56,57]$.

Actin polymerization is involved in cell migration and thus is important in determining the invasiveness ability of cancer cells [56]. Our results showed that Buserelin promoted actin polymerization as stress fibers in WT and Desk191 GnRHR-transfected adherent MDA cells, thus suggesting that activation of the $\mathrm{GnRH} / \mathrm{GnRHR}$ system may be involved in the migratory potential of these malignant cells. Since Buserelin-stimulated MDA cells displayed many stress fibers and high F-actin levels, we analyzed the effects of GnRHa on RhoA, a small GTPase involved in actin polymerization and formation of stress fibers. In fact, previous studies have shown the effect of GnRH on actin cytoskeleton via other members of the Rho GTPases family $[22,23]$. We found that in Collagen I-adherent MDA cells, exposure to GnRHa increased RhoA-GTP levels and paralleled the amount of stress fibers. The effects of GnRH in RhoA-GTP were verified by co-transfection assays employing the GAP domain of p190RhoGAP and its dominant negative mutant, GAP-Y1284D [33]. p190RhoGAP is a specific GAP for RhoA and its effect represents more than $60 \%$ of the overall GAP activity in the cell $[57,58]$. The results showed that GTPase RhoA levels were abolished or unaltered in the presence of the GAP domain or GAP-Y1284D, respectively, thus indicating the specificity of the GnRH/GnRHR system on this particular small $G$ protein. Concurrently, these data indicates that the effects of GnRH on actin polymerization and stress fibers assembly are mediated through activation of RhoA in Collagen I-attached MDA cells.

To demonstrate that GnRH-activated GTP RhoA promotes cell adhesion and thus may represent one of the mechanisms whereby this $G$ protein inhibits cell migration, cell adhesion assays as well as confocal visualization of FA (substrate binding sites) were performed. In fact, previous studies have shown that RhoA activity supports efficient substrate adhesion, reduces cell detachment rate, and attenuates cell locomotion [59-61]. Our results showed that exposure of Collagen-I-adherent MDA cells to the GnRHa promoted cell adhesion to substrate and increased the number of FA. Further, cell invisiveness of these GnRHa-exposed cells was abolished as disclosed by invasion assays in Collagen-I-covered Transwell Chambers.

Actin polymerization leads to membrane protrusion and extracellular cell-matrix adhesion, which are generally considered as markers of the migration capacity of different cell types [62]. In this vein, it was interesting to find that in MDA cells co-transfected with the GnRHR and the GAP domain, stimulation with Buserelin did not promote detectable increments in cell adhesion to substrate - but paradoxically, it increased the levels of F-actin at the periphery of the cells. The observation that GAP domain-cotransfected cells additionally showed membrane protrusions similar to lamellipodia, suggests that continuous activation of other GTPases, such as Rac1, was present in these cells. In fact, previous studies have demonstrated the ability of GnRH to stimulate this particular GTPase [22].

Our findings in MDA cells exposed to GnRH has also been observed in other cell lines, and apparently the effects of this decapeptide on cell migration depend on the cell context. For example, it has been shown that GnRH-mediated attenuation in migration capacity of DU145 cells (prostate cancer-derived) is associated with 
an increase in the amount of stress fibers and with RhoA activation as well. By contrast, in TSU-Pr1 cells (also derived from prostate cancer cells) GnRH favors cell migration through mechanisms mediated by the GTPasas Rac1 and Cdc42, and by formation of filipodia and lamellipodia [23]. Our results suggests that in MDA cells transfected with the GAP domain, the absence of active RhoA GTPase promoted loss of the FA and hence in their ability to adhere to substrate as it was observed in response to GnRHa. In this scenario, the loss of migratory capacity of these cells might have resulted from the relative decrease in RhoA GTPase levels, since it is well known that cell invasion requires the concourse of several small $\mathrm{G}$ proteins [62].

\section{Conclusion}

In the present study, we provide evidence demonstrating that in the highly invasive human breast cancer MDA-MB-231 cell line, activation of the GnRHR promotes RhoA activation, actin cytoskeleton remodeling and a remarkable increase in cell adhesion to substrate. Concurrently, these data may explain the ability of $\mathrm{GnRH}$ to reduce the metastatic potential and invasiveness of malignant breast tumor cells.

\section{Competing interests}

The authors declare no competing interests.

\section{Authors' contributions}

AAR and MHR participated in the study design and the experimental studies. GMN performed the radioligand binding assays and IP production experiments. JV made the GAP domain and GAP-Y1284D DNA constructs. FAV performed the statistical analysis and AAR, AUA, and PMC. participated in the interpretation of the results and preparation of the manuscript. All authors read and approved the final manuscript.

\section{Acknowledgements}

This study was supported by grants 83142 (to AA-R), 61580 (to GM-N), and 86881 (to AU-A) from CONACyT, México, and grants 2007-3606-14 (to AA-R), 2005-1/I/023 (to GM-N) from the FIS-Instituto Mexicano del Seguro Social, México and the National Institutes of Health Grants OD012220-02, DK85040 and OD 011092-53 (PMC). We are grateful to Iván J Galván-Mendoza MSc, from the Unidad de Microscopía Confocal y Multifotónica, CINVESTAV, Mexico, for his technical assistance.

\section{Author details \\ ${ }^{1}$ Centro de Investigación Biomédica del Sur (CIBIS), Instituto Mexicano del Seguro Social (IMSS), Argentina No. 1, Col. Centro, 62790, Xochitepec, Morelos, Mexico. ${ }^{2}$ Research Unit in Reproductive Medicine, Unidad Médica de Alta Especialidad-Hospital de Ginecobstetricia No. 4 "Luis Castelazo Ayala" IMSS, Mexico, DF, Mexico. ${ }^{3}$ Oregon National Primate Research Center, Oregon Health Sciences University, Beaverton, OR, USA. ${ }^{4}$ Division of Reproductive Health, Research Center in Population Health, National Institute of Public Health, Cuernavaca, Morelos, Mexico. ${ }^{5}$ Departament of Biochemistry, Centro de Investigación y de Estudios Avanzados (CINVESTAV), Apartado Postal 14-740, Mexico, DF 07000, Mexico.}

Received: 18 June 2012 Accepted: 25 October 2012

Published: 23 November 2012

\section{References}

1. Parkin DM, Pisani P, Ferlay J: Global cancer statistics. CA Cancer J Clin 1999, 40:33-64.
2. Schally AV, Nagy A: Chemotherapy targeted to cancers through tumoral hormone receptors. Trends Endocrinol Metab 2004, 15:300-310.

3. Wind NS, Holen I: Multidrug resistance in breast cancer: from in vitro models to clinical studies. Int J Breast Cancer 2011, 2011:967419.

4. Lin M, van Golen KL: Rho-regulatory proteins in breast cancer cell motility and invasion. Breast Cancer Res Treat 2004, 84:49-60.

5. Wang $Y$, Zhou BP: Epithelial-mesenchymal transition in breast cancer progression and metastasis. Chin J Cancer 2011, 30:603-611.

6. Brábek J, Mierke $C T$, Rösel D, Veselì P, Fabry B: The role of the tissue microenvironment in the regulation of cancer cell motility and invasion. Cell Commun Signal 2010, 8:22.

7. Aspenström P, Fransson A, Saras J: Rho GTPases have diverse effects on the organization of the actin filament system. Biochem J 2004, 377:327-337.

8. Ridley A, Hall A: The small GTP-binding protein rho regulates the assembly of focal adhesions and actin stress fibers in response to growth factors. Cell 1992, 70:389-399.

9. Arthur WT, Burridge K: RhoA inactivation by p190RhoGAP regulates cell spreading and migration by promoting membrane protrusion and polarity. Mol Biol Cell 2001, 12:2711-2720.

10. Jeon CY, Kim HJ, Lee JY, Kim JB, Kim SC, Park JB: p190RhoGAP and Rapdependent RhoGAP (ARAP3) inactivate RhoA in response to nerve growth factor leading to neurite outgrowth from PC12 cells. Exp Mol Med 2010, 42:335-344.

11. Nobes CD, Hall A: Rho GTPase control polarity, protrusion, and adhesion during cell movement. J Cell Biol 1999, 144:1253-1244.

12. Rousseau M, Gaugler MH, Rodallec A, Bonnaud S, Paris F, Corre I: RhoA GTPase regulates radiation-induced alterations in endothelial cell adhesion and migration. Biochem Biophys Res Commun 2011, 414:750-755.

13. Ilić D, Furuta Y, Kanazawa S, Takeda N, Sobue K, Nakatsuji N, Nomura S, Fujimoto J, Okada M, Yamamoto T: Reduced cell motility and enhanced focal adhesion contact formation in cells from FAK-deficient mice. Nature 1995, 377:539-544

14. Millar RP, Lu ZL, Pawson AJ, Flanagan CA, Morgan K, Maudsley SR: Gonadotropin-releasing hormone receptors. Endocr Rev 2004, 25:235-275.

15. Kahán Z, Nagy A, Schally AV, Halmos G, Arencibia JM, Groot K: Complete regression of MX-1 human breast carcinoma xenografts after targeted chemotherapy with a cytotoxic analog of luteinizing hormone-releasing hormone, AN-207. Cancer 1999, 85:2608-2615.

16. Kahán Z, Nagy A, Schally AV, Halmos G, Arencibia JM, Groot K Administration of a targeted cytotoxic analog of luteinizing hormonereleasing hormone inhibits growth of estrogen-independent MDA-MB231 human breast cancers in nude mice. Breast Cancer Res Treat 2000, 59:255-262

17. Moretti RM, Montagnani MM, Van Groeninghen JC, Limonta P: Locally expressed LHRH receptor mediate the oncostatic and antimetastastic activity of LHRH agonists on melanoma cells. J Clin Endocrinol Metab 2002, 87:3791-3797.

18. Miller WR, Scott WN, Morris R, Fraser HM, Sharpe RM: Growth of human breast cancer cells inhibited by a luteinizing hormone-releasing hormone agonist. Nature 1985, 313:231-233.

19. Nagy A, Schally AV: Targeting of cytotoxic luteinizing hormone-releasing hormone analogs to breast, ovarian, endometrial, and prostate cancers. Biol Reprod 2005, 73:851-859.

20. von Alten J, Fister S, Schulz H, Viereck V, Frosch KH, Emons G, Gründker C: $\mathrm{GnRH}$ analogs reduce invasiveness of human breast cancer cells. Breast Cancer Res Treat 2006, 100:13-21.

21. Schubert A, Hawighorst T, Emons G, Gründker C: Agonists and antagonists of $\mathrm{GnRH}-\mathrm{I}$ and -II reduce metastasis formation by triple-negative human breast cancer cells in vivo. Breast Cancer Res Treat 2011, 130:783-790.

22. Davidson L, Pawson AJ, Millar RP, Maudsley S: Cytoskeletal reorganization dependence of signaling by the gonadotropin-releasing hormone receptor. J Biol Chem 2004, 279(1980):1993.

23. Enomoto M, Utsumi M, Park MK: Gonadotropin-releasing hormone induces actin cytoskeleton remodeling and affects cell migration in a cell-type-specific manner in TSU-Pr1 and DU145 cells. Endocrinology 2006, 147:530-542.

24. Yates $C$, Wells A, Turner T: Luteinising hormone-releasing hormone analogue reverses the cell adhesion profile of EGFR overexpressing DU-145 human prostate carcinoma subline. Br J Cancer 2005, 92:366-375.

25. Dobkin-Bekman M, Naidich M, Rahamim L, Przedecki F, Almog T, Lim S, Melamed P, Liu P, Wohland T, Yao Z, et al: A preformed signaling complex 
mediates GnRH-activated ERK phosphorylation of paxillin and FAK at focal adhesions in L beta T2 gonadotrope cells. Mol Endocrinol 2009, 23:1850-1864

26. Eidne KA, Flanagan CA, Millar RP: Gonadotropin-releasing hormone binding sites in human breast carcinoma. Science 1985, 229:989-991.

27. Eidne KA, Flanagan CA, Harris NS, Millar RP: Gonadotropin-releasing hormone (GnRH)-binding sites in human breast cancer cell lines and inhibitory effects of GnRH antagonists. J Clin Endocrinol Metab 1987, 64:425-432.

28. Morishige M, Hashimoto S, Ogawa E, Toda Y, Kotani H, Hirose M, Wei S, Hashimoto A, Yamada A, Yano H, et al: GEP100 links epidermal growth factor receptor signalling to Arf6 activation to induce breast cancer invasion. Nat Cell Biol 2008, 10:85-92.

29. Chi L, Zhou W, Prikhozhan A, Flanagan C, Davidson JS, Golembo M, Illing N, Millar RP, Sealfon SC: Cloning and characterization of the human GnRH receptor. Mol Cell Endocrinol 1993, 91:R-1-R-6.

30. Maya-Nunez G, Janovick JA, Ulloa-Aguirre A, Soderlund D, Conn PM, Mendez JP: Molecular basis of hypogonadotropic hypogonadism: restoration of mutant $(\mathrm{E}(90) \mathrm{K}) \mathrm{GnRH}$ receptor function by a deletion at a distant site. J Clin Endocrinol Metab 2002, 87(5):2144-2149.

31. Maya-Núñez G, Janovick JA, Conn PM: Combined modification of intracellular and extracellular loci on human gonadotropin-releasing hormone receptor provides a mechanism for enhanced expression. Endocrine 2000, 13:401-407.

32. Tikoo A, Czekay S, Viars C, White S, Heath JK, Arden K, Maruta H: p190-A, a human tumor suppressor gene, maps to the chromosomal region $19 q 13.3$ that is reportedly deleted in some gliomas. Gene 2000, 257:23-31.

33. Haskell MD, Nickles AL, Agati JM, Su L, Dukes BD, Parsons SJ: Phosphorylation of $\mathrm{p} 190$ on Tyr1105 by c-Src is necessary but not sufficient for EGF-induced actin disassembly in $\mathrm{C} 3 \mathrm{H} 10 \mathrm{~T} 1 / 2$ fibroblasts. J Cell Sci 2001, 114:1699-1708.

34. Maya-Núñez G, Janovick JA, Aguilar-Rojas A, Jardón-Valadez E, LeañosMiranda A, Zariñan T, Ulloa-Aguirre A, Conn PM: Biochemical mechanism of pathogenesis of human gonadotropin-releasing hormone receptor mutants Thr104lle and Tyr108Cys associated with familial hypogonadotropic hypogonadism. Mol Cell Endocrinol 2011, 337:16-23.

35. Huckle WR, Conn PM: Use of lithium ion in measurement of stimulated pituitary inositol phospholipid turnover. Methods Enzymol 1987, 141:149-155.

36. Menu E, Braet F, Timmers M, Van Riet I, Van Camp B, Vanderkerken K: The Factin content of multiple myeloma cells as a measure of their migration. Ann N Y Acad Sci 2002, 973:124-136.

37. Defacque $H$, Egeberg $M$, Habermann A, Diakonova M, Roy C, Mangeat $P$, Voelter W, Marriott G, Pfannstiel J, Faulstich H, et al: Involvement of ezrin/ moesin in de novo actin assembly on phagosomal membranes. EMBO $\lrcorner$ 2000, 19:199-212.

38. Condeelis J, Hall A: Measurement of actin polymerization and crosslinking in agonist-stimulated cells. Methods Enzymol 1991, 196:486-493.

39. Chen WT, Singer SI: Immunoelectron microscopic studies of the sites of cell-substratum and cell-cell contacts in cultured fibroblasts. J Cell Biol 1982, 95:205-222.

40. Benard V, Bokoch GM: Assay of Cdc42, Rac, and Rho GTPase activation by affinity methods. Methods Enzymol 2002, 345:349-359.

41. Kim HJ, Kim JB, Lee KM, Shin I, Han W, Ko E, Bae JY, Noh DY: Isolation of CD24(high) and CD24(low/-) cells from MCF-7: CD24 expression is positively related with proliferation, adhesion and invasion in MCF-7. Cancer Lett 2007, 258:98-108.

42. Harvath L: Assay for filamentous actin. Methods Mol Biol 1994, 34:261-268.

43. Shaw LM: Tumor cell invasion assays. Methods Mol Biol 2005, 294:97-105.

44. Ottoson NC, Pribila JT, Chan AS, Shimizu Y: Cutting edge: T cell migration regulated by CXCR4 chemokine receptor signaling to ZAP-70 tyrosine kinase. J Immunol 2001, 167:1857-1861.

45. Ridley A, Hall A, Zamir E, Geiger B: Molecular complexity and dynamics of cell-matrix adhesions. J Cell Sci 2001, 114:3583-3590.

46. Chrzanowska-Wodnicka M, Burridge K: Rho-stimulated contractility drives the formation of stress fibers and focal adhesions. J Cell Biol 1996, 133:1403-1415.

47. Kanchanawong P, Shtengel G, Pasapera AM, Ramko EB, Davidson MW, Hess HF, Waterman CM: Nanoscale architecture of integrin-based cell adhesions. Nature 2010, 468:580-584.
48. Ferlay J, Autier P, Boniol M, Heanue M, Colombet M, Boyle P: Estimates of the cancer incidence and mortality in Europe in 2006. AnnOncol 2007, 18:581-592.

49. McGuire WL: Prognostic factors for recurrence and survival in human breast cancer. Breast Cancer Res Treat 1987, 10:5-9.

50. Finch AR, Sedgley KR, Caunt CJ, McArdle CA: Plasma membrane expression of $\mathrm{GnRH}$ receptors: regulation by antagonists in breast, prostate, and gonadotrope cell lines. J Endocrinol 2008, 196:353-367.

51. Morgan K, Meyer C, Miller N, Sims AH, Cagnan I, Faratian D, Harrison DJ, Millar RP, Langdon SP: GnRH receptor activation competes at a low level with growth signaling in stably transfected human breast cell lines. BMC Cancer 2011, 11:476.

52. Everest HM, Hislop JN, Harding T, Uney JB, Flynn A, Millar RP, McArdle CA: Signaling and antiproliferative effects mediated by $\mathrm{GnRH}$ receptors after expression in breast cancer cells using recombinant adenovirus. Endocrinology 2001, 142:4663-4672.

53. Limonta P, Moretti RM, Marelli MM, Dondi D, Parenti M, Motta M: The luteinizing hormone-releasing hormone receptor in human prostate cancer cells: messenger ribonucleic acid expression, molecular size, and signal transduction pathway. Endocrinology 1999, 140(11):5250-5256.

54. Maudsley S, Davidson L, Pawson AJ, Chan R, De Lopez Maturana R, Millar RP: Gonadotropin-releasing hormone $(\mathrm{GnRH})$ antagonists promote proapoptotic signaling in peripheral reproductive tumor cells by activating a Galphai-coupling state of the type I GnRH receptor. Cancer Res 2004, 64(20):7533-7544

55. Grundker C, Volker P, Emons G: Antiproliferative signaling of luteinizing hormone-releasing hormone in human endometrial and ovarian cancer cells through $\mathrm{G}$ protein alpha(I)-mediated activation of phosphotyrosine phosphatase. Endocrinology 2001, 142(6):2369-2380.

56. Yamaguchi $\mathrm{H}$, Condeelis J: Regulation of the actin cytoskeleton in cancer cell migration and invasion. Biochim Biophys Acta 2007, 1773(5):642-652.

57. Fincham VJ, Chudleigh A, Frame MC: Regulation of p190 Rho-GAP by vSrc is linked to cytoskeletal disruption during transformation. J Cell Sci 1999, 112:947-956.

58. Vincent S, Settleman J: Inhibition of RhoGAP activity is sufficient for the induction of Rho-mediated actin reorganization. Eur J Cell Biol 1999, 78:539-548.

59. Cox EA, Huttenlocher A: Regulation of integrin-mediated adhesion during cell migration. Microsc Res Tech 1998, 43(5):412-419.

60. Palecek SP, Huttenlocher A, Horwitz AF, Lauffenburger DA: Physical and biochemical regulation of integrin release during rear detachment of migrating cells. J Cell Sci 1998, 111(Pt 7):929-940.

61. Dourdin N, Bhatt AK, Dutt P, Greer PA, Arthur JS, Elce JS, Huttenlocher A: Reduced cell migration and disruption of the actin cytoskeleton in calpaindeficient embryonic fibroblasts. J Biol Chem 2001, 276(51):48382-48388.

62. Le Clainche C, Carlier MF: Regulation of actin assembly associated with protrusion and adhesion in cell migration. Physiol Rev 2008, 88(2):489-513.

doi:10.1186/1471-2407-12-550

Cite this article as: Aguilar-Rojas et al: Gonadotropin-releasing hormone receptor activates GTPase RhoA and inhibits cell invasion in the breast cancer cell line MDA-MB-231. BMC Cancer 2012 12:550.

\section{Submit your next manuscript to BioMed Central and take full advantage of:}

- Convenient online submission

- Thorough peer review

- No space constraints or color figure charges

- Immediate publication on acceptance

- Inclusion in PubMed, CAS, Scopus and Google Scholar

- Research which is freely available for redistribution 